\title{
Plasma motilin, gastrin, and enteroglucagon and feeding in the human newborn
}

\author{
A LUCAS, T E ADRIAN, N CHRISTOFIDES, S R BLOOM, AND A AYNSLEY-GREEN \\ University Department of Paediatrics, John Radcliffe Hospital, Oxford, and \\ Hammersmith Hospital, London
}

SUMMARY Plasma concentrations of motilin, gastrin, and enteroglucagon were measured in cord blood and during the first 24 days of life before feeding in 45 term and 63 preterm, healthy infants. Levels of these hormones rose steeply after birth, reaching concentrations that were much higher than those in fasting adults. These increases in hormone concentration were not present in a group of 10 preterm infants who had received only intravenous dextrose from birth because of hyaline membrane disease. Our findings suggest that early enteral feeding may trigger the postnatal increase in plasma concentrations of gut hormones and that this could play an important role in the physiological adaptations to extrauterine nutrition.

At birth intravenous nutrition via the placenta ceases and the neonate must adapt to enteral feeding. By age 2 weeks the term neonate consumes a daily volume of milk which in an adult, on a proportionate body weight basis, would correspond to a fluid intake of 10-20 litres a day. Clearly the periodic administration of these large volumes of milk to neonates must necessitate adjustments in their gastrointestinal motility, and there is evidence to suggest that gastric emptying and upper intestinal transit time become more rapid during the first weeks of life both in term and preterm infants. ${ }^{1}$ In addition, animal studies demonstrate that early enteral feeding results in pronounced changes in the structure and growth of the alimentary tract, associated with enchancement of enzyme activities-for example in jejunal lactase and acid phosphatase: in contrast, these changes are not seen in unfed animals. ${ }^{2-4}$

The triggering mechanism for the physiological and structural changes that occur after birth in the gastrointestinal tract of the human newborn is poorly understood, but it is possible that the secretion of gut hormones in response to enteral food plays a key role. We have studied 3 hormones (motilin, enteroglucagon, and gastrin) in the neonatal period.

Motilin contains 22 amino-acids and is produced by endocrine cells of the upper small intestine. ${ }^{5}$ Since this peptide was isolated in $1971^{6}$ there has been evidence to suggest that it is physiologically important in the control of gastrointestinal motility in adult man. ${ }^{7-8}$
Gastrin, released from specific endocrine cells in the pyloric antrum and duodenum, ${ }^{9}$ and enteroglucagon, produced in highest concentrations in the ileum and colon, are of particular interest in the neonatal period because, in addition to their other functions, they may exert a trophic influence on the gastrointestinal tract (see below).

In order to investigate the roles of motilin, enteroglucagon, and gastrin in the postnatal adaptation to enteral nutrition, we have measured plasma levels of these peptides in more than 100 term and preterm infants.

\section{Patients and sampling procedure}

63 preterm infants (birthweights $1950 \pm 30 \mathrm{~g}$ (mean \pm SEM) and gestations $33.5 \pm 0.1$ weeks) and 45 term infants (birthweights $3312 \pm 50 \mathrm{~g}$ and gestations $39 \cdot 5 \pm 0.1$ weeks) were studied, with the approval of the ethics committee. Each infant contributed only one venous blood sample; this was taken either at birth (cord blood, at normal vaginal delivery) or postnatally. Postnatal samples were obtained from the back of the hand using an open needle technique, and were taken only at a time when blood was also required for clinical monitoring. Term infants were sampled either before the first feed at age 4-6 hours, or on day 6 (range 5-7), or day 16 (range 12-24); preterm infants were sampled before the first feed at age 3-6 hours, or on day $2 \frac{1}{2}$ (1-4), day $6(5-7)$, day $13(11-17)$, or day 24 (18-42). In each group samples were taken 
immediately before feeding. Term infants were breast-fed over 25-35 minutes at 4-hourly intervals. Preterm infants were fed pooled human milk over 5 minutes via a nasogastric tube as previously described. ${ }^{10}$ Infants aged $2 \frac{1}{2}$ days were fed 2-hourly; infants aged 6, 13, and 24 days were fed 3-hourly.

In addition, 10 preterm infants were studied (ages $6 \cdot 2 \pm 0 \cdot 5$ days, birthweights $1875 \pm 243 \mathrm{~g}$, gestations $33 \pm 1$ weeks) who had hyaline membrane disease and lacked the ability to tolerate enteral fluids: they had received only intravenous dextrose since birth. They required ventilatory assistance and enriched inspired oxygen but each had a $\mathrm{PaO}_{2}$ between 60 and 90 mmHg (7.9-11.9 kPa), $\mathrm{pH}>7 \cdot 25$, and each was clinically stable at the time of the study. Blood was also collected from 12 healthy, fasting adults.

\section{Methods}

Venous blood samples $(2 \mathrm{ml})$ were collected into cooled heparin-coated tubes containing aprotonin (Trasylol, Bayer: $2000 \mathrm{KIU}$ ); the plasma was separated after centrifugation at $4^{\circ} \mathrm{C}$ within 20 minutes of collection. All samples were stored at $-20^{\circ} \mathrm{C}$ and assayed at the same time. Motilin was measured by radioimmunoassay, as described by Bloom et al.,11 using an antiserum diluted 1:320 000 which showed no cross-reaction with any other hormone and which could detect changes between single plasma samples of $3 \mathrm{pmol} / \mathrm{l}$ with $95 \%$ confidence. Gastrin was measured using the radioimmunoassay described previously. ${ }^{12}$ The antibody measured fully both big and little gastrin, although not 'big big gastrin' or cholecystokinin, and could detect changes between individual samples of 4 $\mathrm{pmol} / \mathrm{l}$. As human enteroglucagon is not available in pure form an indirect radioimmunoassay method was used. ${ }^{13}$ Two antiglucagon antibodies were used, one of which cross-reacted totally with gut glucagonlike material-for example one which detects pure porcine 'glycentin' fully-and one which was specific for pancreatic glucagon-for example gives zero readings in total pancreatotic patients. The enteroglucagon levels were derived from the difference between these two assays. Changes of $6 \mathrm{pmol} / \mathrm{l}$ were detectable in this assay system.

Statistical analyses were performed using the nonparametric Mann-Whitney rank sum test, but for ease of comparison, mean and standard errors are given in both text and figures.

\section{Results}

Motilin. Mean cord plasma motilin concentration in 20 term infants was $32 \pm 4$ (mean \pm SEM) pmol/l, significantly higher than in 6 preterm infants, $13 \pm 4$

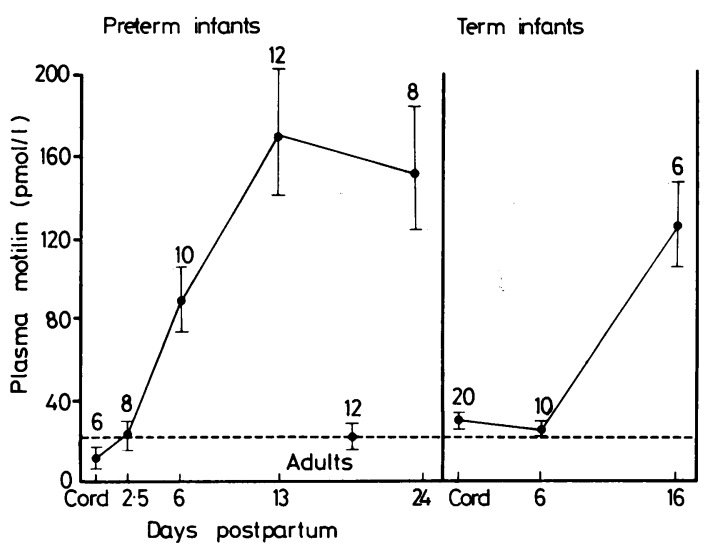

Fig. 1 Plasma motilin concentrations (pmol $/ \pm S E M$ ) in preterm (left) and term (right) infants at birth (venous cord blood) and postnatally (before a feed). Number of observations in each group is shown above standard error bars. Dotted line represents fasting adult value.

$(P<0.02)$. No significant change had occurred in plasma levels by 3-6 hours of age before the first feed in either term $(26 \pm 3)$ or preterm $(14 \pm 4)$ infants.

In preterm infants plasma motilin rose from the cord level of $13 \pm 4 \mathrm{pmol} / \mathrm{l}$ to basal concentrations of $89 \pm 16 \mathrm{pmol} / 1$ on day $6(\mathrm{P}<0.01)$ and to $150 \pm 30$ pmol/1 on day $24(P<0.001)$, Fig. 1. In contrast, by day 6 preterm infants who had not been fed orally did not show this pronounced motilin increase; their mean plasma motilin level was $24 \pm 4$ pmol, significantly lower than the orally-fed preterm infants at this time after birth $(P<0 \cdot 001)$, Fig. 4.

Breast-fed term infants aged 6 days had motilin levels $(26 \pm 3$ pmol) similar to the cord level, but by day 16 the level had risen to $123 \pm 24$ pmol, $\mathrm{P}<0.001$ (Fig. 1). Basal motilin was higher in 6-day-old preterm infants than in term ones $(\mathrm{P}<0.001)$.

The plasma motilin concentration in the 12 adults was $22 \pm 6 \mathrm{pmol} / \mathrm{l}$, significantly lower than levels reached at 16 days in term infants $(P<0.001)$ and at 24 days in preterm infants $(P<0 \cdot 001)$, Fig. 1 .

Gastrin. Plasma gastrin concentrations were similar in the cord blood of term $(42 \pm 5 \mathrm{pmol} / \mathrm{l})$ and preterm $(38 \pm 7)$ infants, and both these levels were significantly higher than the mean fasting adult control value, $7 \pm 2(P<0 \cdot 001)$ Fig. 2 . By $3-6$ hours of age the mean plasma gastrin level had fallen from the cord level to $12 \pm 2 \mathrm{pmol} / \mathrm{l}$ in preterm infants and to $11 \pm 1 \mathrm{pmol} / 1$ in term ones; levels rose to peak on day 6 to $54 \pm 8(P<0 \cdot 001)$. Concentrations were still significantly above adult levels by 16 days in term infants $(P<0.001)$ and by 24 days in preterm ones 


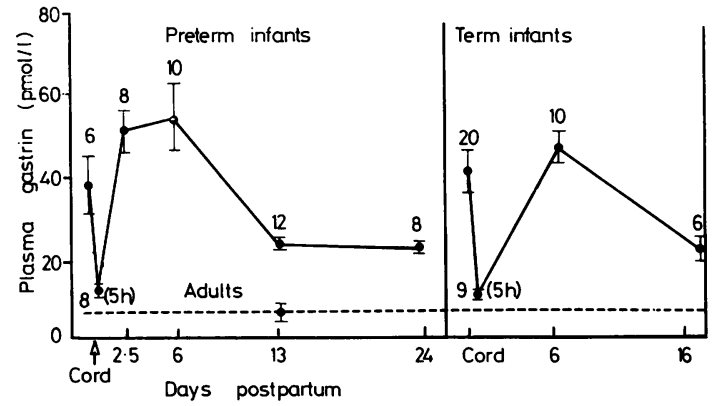

Fig. 2 Plasma gastrin concentrations (pmol/l土SEM) in preterm (left) and term (right) infants at birth (venous cord blood) and postnatally (before a feed). Number of observations in each group is shown above standard error bars. Dotted line represents fasting adult value.

$(\mathrm{P}<0.001)$, Fig. 2. In contrast, in 6-day-old preterm infants who had not been fed orally, there was only a small increase in plasma gastrin $(21 \pm 4)$ above the level before the first feed at age 3-6 hours, Fig. 4 $(\mathrm{P}<0 \cdot 05)$.

Enteroglucagon. Cord plasma enteroglucagon concentrations were similar in term and preterm infants $(77 \pm 5$ and $80 \pm 7 \mathrm{pmol} / 1$ respectively) and were slightly above the adult level of $37 \pm 5(P<0 \cdot 05)$, Fig. 3. Plasma concentrations at age 3-6 hours were unchanged in term and preterm infants (term $64 \pm 8$, preterm $60 \pm 10$ ). The postnatal increase above the cord level in basal plasma enteroglucagon reached a peak in fed preterm infants of $369 \pm 62$ by

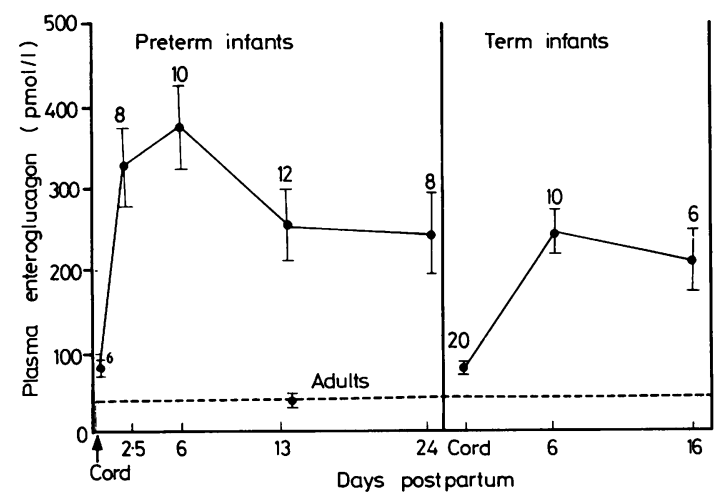

Fig. 3 Plasma enteroglucagon concentrations (pmol/l \pm $S E M)$ in preterm (left) and term (right) infants at birth (venous cord blood) and postnatally (before a feed). Number of observations in each group is shown above standard error bars. Dotted line represents fasting adult value.

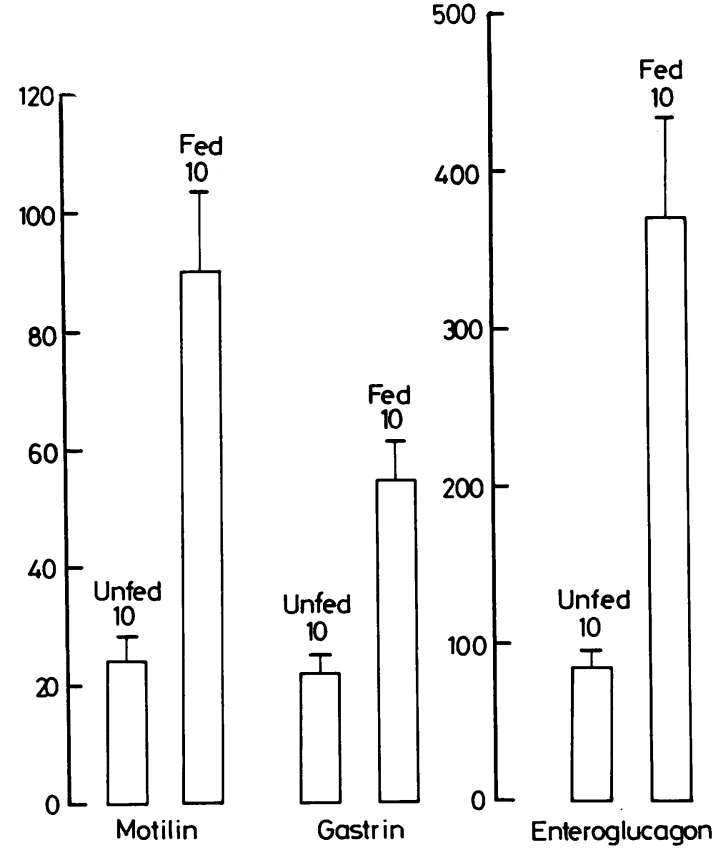

Fig. 4 Basal plasma concentrations of motilin, gastrin, and enteroglucagon (pmol/l $\pm S E M$ ) on day 6 after birth in healthy fed preterm infants (right-hand data bar of each pair) compared with concentrations in infants who had never received enteral feeds because they had hyaline membrane disease (left-hand data bar of each pair).

day $6(\mathrm{P}<0.0001)$, and in 6-day-old term infants reached $202 \pm 26(\mathbf{P}<0 \cdot 0001)$, Fig. 3. There was no rise however in the 6-day-old unfed group $(85 \pm 10)$, Fig. 4.

\section{Discussion}

These studies show that there is a pronounced postnatal increase in basal plasma concentrations of motilin, gastrin, and enteroglucagon. The basal levels of these 3 peptides achieved during the neonatal period both in term and preterm healthy infants far exceed the levels found in healthy fasting adults, and are greater than the adult postprandial concentrations reported by this laboratory. ${ }^{14}$

Motilin has been demonstrated in adults to decrease small intestinal transit time, ${ }^{7}$ and can initiate the formation of new interdigestive myoelectric complexes. ${ }^{8}$ It is possible that the increasing efficiency of motor function of the gut that occurs during the neonatal period ${ }^{1}$ is at least partly due to the high circulating concentrations of motilin. High plasma motilin levels have been reported in infancy 
and childhood only once before..$^{15}$ Our studies show clearly however, that an increase in plasma motilin is a postnatal event, which may have been due to enteral feeding, since motilin concentrations in the group of infants who had received only intravenous dextrose from birth were not raised, although the presence of hyaline membrane disease in these unfed infants could have been a contributory factor. It was interesting to note a slower postnatal rise in motilin in term infants than in preterm ones, with significantly lower levels on day 6 in the term group. Indeed enteroglucagon also tended to be lower in 6-day-old term infants than in preterm ones. It is possible that our findings relate to the relatively low milk intakes in the first few days of life in breast-fed infants.

Hypergastrinaemia at birth or during the neonatal period has been reported by others. ${ }^{16-18}$ The studies of Euler et al. ${ }^{16}$ suggest that the high levels of gastrin at delivery are of fetal rather than maternal origin and may relate to vagal stimulation due to multiple factors at birth. They showed a fall in gastrin after delivery, whereas others ${ }^{17}$ have shown a rise. Our data appear to resolve these conflicting reports as we show that in the first 3-6 hours of life there is a rapid fall in plasma gastrin decreasing to adult levels, and that subsequently there is a substantial rise in the plasma level which then persists throughout the neonatal period. The relationship between gastrin release and gastric acid output in the newborn period has received considerable attention, yet is ill understood. The pattern of acid secretion during the first days of life is both complex ${ }^{19-20}$ and disputed. ${ }^{16}$ However, since the group of infants in our study who had not been enterally fed showed little rise in postnatal gastrin, our findings suggest that, apart from the initial hypergastrinaemia at the time of delivery, the presence of food in the gut may be the important factor in maintaining the persistently high levels of gastrin found in neonates. This hypothesis is supported by the observation that high gastrin levels occur in neonates after the first feed. ${ }^{21-22}$ Gastrin has been shown to exert a trophic effect on the fundic mucosa, where it increases deoxyribonucleic acid, ribonucleic acid, and protein synthesis, ${ }^{23-24}$ and in rats it stimulates exocrine pancreatic growth. ${ }^{25}$ Johnson and Guthrie ${ }^{26}$ showed that both big gastrin (G34) and little gastrin (G17) have similar trophic actions, and each is measured in approximately equimolar quantities by our assay system, although the circulating molecular forms of gastrin in neonates have not been studied. It is likely that the high circulating levels of gastrin we have observed play a part in the trophic changes in the alimentary tract which occur in fed neonates.

There is little information on plasma enteroglucagon in the human neonate. The molecular forms of this hormone have not been characterised fully and its true physiological actions have yet to be defined. However, a limited amount of evidence suggests that enteroglucagon may be a trophic factor for the gut. Gleeson et al. ${ }^{27}$ reported striking villous hypertrophy in the small bowel resulting from an enteroglucagon-producing tumour of the kidney, and others have shown that small bowel resection ${ }^{28}$ and ileal bypass surgery ${ }^{29}$ result in high circulating enteroglucagon levels, suggesting a possible feedback mechanism for stimulating gut growth. The massive enteroglucagon levels seen in term and preterm neonates appear, like motilin and gastrin, to be related to enteral feeding and may be important in stimulating postnatal structural changes in the intestine.

Why basal plasma concentrations of gastrin, enteroglucagon, and motilin should reach such high levels in the neonate is unknown, but we have considered several possible causes. Raised plasma levels could reflect the relatively greater length of the gut found in neonates compared with adults. ${ }^{30}$ Alternatively, plasma clearance mechanisms may be less effective at this age, although this would be inconsistent with the rapid early fall in plasma gastrin we have described. In the case of enteroglucagon, some degree of malabsorption with undigested food reaching the large bowel could stimulate excessive colonic enteroglucagon release, a situation reminiscent of the high enteroglucagon levels seen in coeliac disease. ${ }^{14}$ The small feed-to-feed interval, together with the relative large feed volume in the neonate compared with the adult, might also result in persistently high basal gut hormone levels, yet Sann et al. ${ }^{18}$ observed that postprandial gastrin levels were no different in infants who were fed either 4- or 6-hourly. Finally, it is possible that the 'release setting' of gut endocrine cells differs in neonates and adults, so that a given enteral stimulus produces a greater hormone release from each endocrine cell in the neonate.

In view of the evidence presented for the proposed physiological actions of motilin, gastrin, and enteroglucagon, it is possible that the postnatal increase in these hormones plays an important part in inducing developmental changes in the gastrointestinal tract that equip the newborn infant for enteral feeding. In addition, our data suggest that enteral feeding itself may trigger the rise in these gut hormones after birth, and so provide further insight into the physiology of early infant feeding. In addition they form a basis for the assessment of the pathophysiological effects of delaying the onset of enteral nutrition in the management of the high risk neonate, and also of surgical resections of the gut in the newborn period. 


\section{References}

1 Smith C A. Physiology of the digestive tract. In: Smith $\mathrm{C} \mathrm{A}$, Nelson $\mathrm{N} \mathrm{M}$, eds. The physiology of the newborn infant. Springfield, Illinois: Thomas, 1976: 259-79.

2 Lichtenberger L, Johnson L R. Gastrin in the ontogenic development of the small intestine. Am J Physiol 1974; 227: 391-5.

3 Stoddart R W, Widdowson E M. Changes in the organs of pigs in response to feeding for the first 24 hours after birth. III. Fluorescent histochemistry of the carbohydrate of the intestine. Biol Neonate 1976; 29: 18-27.

4 Widdowson E M, Colombo V E, Artavanis C A. Changes in the organs of pigs in response to feeding for the first 24 hours after birth. II. The digestive tract. Biol Neonate 1976; 28: 272-81.

- Pearse A G E, Polak J M, Bloom S R, Adams C, Dryburgh J R, Brown J C. Enterochromaffin cells of the mammalian intestine as the source of motilin. Virchows Archiv (Cell Pathol) 1974; 16: 111-20.

- Brown J C, Mutt V, Dryburgh J R. The further purification of motilin, a gastric motor activity stimulating polypeptide from the mucosa of the small intestine of hogs. Can J Physiol Pharmacol 1971; 49: 399-405.

7 Rüppin $\mathrm{H}$, Sturm G, Westhoff $\mathrm{D}$, et al. Effect of 13Nle-motilin on small intestinal transit time in healthy subjects. Scand J Gastroenterol (Suppl) 1976; 11 : No 39, 85-8.

8 Vantrappen G, Janssens J, Peeters J, Bloom S R, Christofides N D, Hellemans J. Intraduodenal pH, motilin, and interdigestive motor complex in man (abstract). Scand J Gastroenterol (Suppl) 1978; 13: No 49, 190.

- Lechago J, Weinstein W M. Morphological aspects of the G-cells. In: Bloom S R, ed. Gut hormones. Edinburgh: Churchill Livingstone, $1978 ; 140-4$.

10 Lucas A, Bloom S R, Aynsley-Green A. Metabolic and endocrine events at the time of the first feed of human milk in preterm and term infants. Arch Dis Child 1978; 53: 731-6.

11 Bloom S R, Mitznegg P, Bryant M G. Measurement of human plasma motilin. Scand J Gastroenterol (Suppl) 1976 ; 11 : No 39, 47-52.

12 Russell R C G, Bloom S R, Fielding L P, Bryant M G. Current problems in the measurement of gastrin release; a reproducible measure of physiological gastrin release. Postgrad Med J 1976; 52: 645-50.

13 Thompson J P S, Bloom S R. Plasma enteroglucagon and plasma volume change after gastric surgery. Clin Sci Mol Med 1976; 51 : 177-83.

14 Besterman H S, Bloom S R, Sarson D L, et al. Guthormone profile in coeliac disease. Lancet 1978; i: 785-8.

15 Mitznegg P, Domschke W, Bloom S R, et al. Physiology of motilin I. In: Bloom S R, ed. Gut hormones. Edinburgh: Churchill Livingstone, 1978; 339-42.
16 Euler A R, Byrne W J, Cousins L M, Ament M E, Leake $R$ D, Walsh J D. Increased serum gastrin concentrations and gastric acid hyposecretion in the immediate newborn period. Gastroenterology 1977; 72: 1271-3.

17 Rogers I M, Davidson D C, Lawrence J, Ardill J, Buchanan K D. Neonatal secretion of gastrin and glucagon. Arch Dis Child 1974; 49: 796-801.

18 Sann L, Chayvialle J A, Bremond A, Lambert R. Serum gastrin level in early childhood. Arch Dis Child 1975; 50: 782-5.

19 Ebers D W, Smith D I, Gibbs G E. Gastric acidity on the first day of life. Pediatrics $1956 ; 18$ : 800-2.

20 Harries J T, Fraser A J. The acidity of the gastric contents of premature babies during the first fourteen days of life. Biol Neonate 1968; 12: 186-93.

21 Aynsley-Green A, Bloom S R, Williamson D H, Turner R C. Endocrine and metabolic response in the human newborn to first feed of breast milk. Arch Dis Child 1977; 52: 291-5.

22 von Berger L, Henrichs I, Raptis S, et al. Gastrin concentration in plasma of the neonate at birth and after the first feeding. Pediatrics 1976; 58: 264-7.

23 Johnson $\mathbf{L} \mathbf{R}$. The trophic action of gastrointestinal hormones. Gastroenterology 1976; 70: 278-88.

24 Johnson $\mathbf{L}$. New aspects of the trophic action of gastrointestinal hormones. Gastroenterology 1977; 72: 788-92.

25 Mayston P D, Barrowman J A. The influence of chronic administration of pentagastrin on the rat pancreas. $Q J$ Exp Physiol 1971; 56: 113-22.

26 Johnson L R, Guthrie P D. Stimulation of DNA synthesis by big and little gastrin (934 and 917). Gastroenterology 1976; 71 : 599-602.

27 Gleeson M H, Bloom S R, Polak J M, Henry K, Dowling $R$ M. An endocrine tumour in kidney affecting small bowel structure, motility, and absorptive function. Gut 1971 ; 12 : 773-82.

28 Besterman H S, Bloom S R, Adman T E, et al. Gut hormone profile after gut resection (abstract). Gut 1978; 19: 972-3.

29 Besterman H S, Sarson D L, Blackburn A M, Cleary J, Pilkington T R, Bloom S R. The gut hormone profile in morbid obesity and following jejuno-ileal bypass (abstract). Scand J Gastroenterol (Suppl) 1978; 13: No 49, 15.

${ }^{30}$ Koldovský O. Development of the functions of the small intestine in mammals and man. Basel: Karger, 1969.

Correspondence to Dr A Lucas, University Department of Paediatrics, Addenbrooke's Hospital, Hills Road, Cambridge CB2 2QQ.

Received 4 September 1979 